\title{
Norois
}

Environnement, aménagement, société

$190 \mid 2004 / 1$

Varia

\section{Réseaux de villes et réseaux culturels dans l'Ouest}

l'exemple du théâtre et de la musique classique

Jean-Pierre Wolff

\section{CpenEdition}

Journals

Édition électronique

URL : http://journals.openedition.org/norois/81

DOI : $10.4000 /$ norois.81

ISBN : 978-2-7535-1538-3

ISSN : 1760-8546

Éditeur

Presses universitaires de Rennes

\section{Édition imprimée}

Date de publication : 1 janvier 2004

Pagination : 97-109

ISBN : 978-2-86847-939-6

ISSN : 0029-182X

\section{Référence électronique}

Jean-Pierre Wolff, «Réseaux de villes et réseaux culturels dans l'Ouest », Norois [En ligne], 190 | 2004/1, mis en ligne le 03 septembre 2008, consulté le 19 avril 2019. URL : http:// journals.openedition.org/norois/81 ; DOI : 10.4000/norois.81

Ce document a été généré automatiquement le 19 avril 2019

(c) Tous droits réservés 


\title{
Réseaux de villes et réseaux culturels dans l'Ouest
}

\author{
l'exemple du théâtre et de la musique classique
}

\author{
Jean-Pierre Wolff
}

1 Avec l'accélération de la construction européenne, la montée en puissance des grandes métropoles européennes et l'apparition d'un sentiment régional, le devenir du Grand Ouest - Basse-Normandie, Bretagne et Pays de la Loire - questionne les élus, les aménageurs et les chercheurs depuis quelques années. La création en avril 1990 de la Commission Arc Atlantique, animée en particulier par Olivier Guichard (1986), promoteur des politiques d'aménagement volontariste du territoire, accompagne celle des réseaux de villes dans l'Ouest. La position périphérique de ces trois régions par rapport aux grands centres de décision européens, le maintien d'une ruralité assez forte et la présence d'une armature urbaine relativement équilibrée mais dans laquelle n'émerge pas une métropole-capitale, fragilisent cet ensemble géographique et soulèvent des interrogations pour son développement économique et global. Ces éléments géographiques aux incidences économiques non négligeables en matière d'accès aux marchés et aux centres de décision de l'Europe contribuèrent aussi à la mise en place de plusieurs réseaux de villes.

2 L'ensemble de ces éléments relayés par un modèle européen de seuils démographiques à atteindre pour se positionner économiquement et par une volonté nationale de renouvellement de la politique d'aménagement du territoire implique ces mises en réseau sur les plans économique et institutionnel. De nombreux travaux participent à ce questionnement scientifique. Que ce soit la question des réseaux physiques et matériels avec les travaux de Dupuy $(1991,2000)$ et de Merlin (1991), celle statistique et géographique des réseaux de villes avec Bonneville (1996), Lévy (1996) et Cattan, Rozenblat, Saint-Julien et Pumain (1994), Offner et Pumain (1996), des réseaux économiques ou des réseaux sociaux avec l'approche sociologique de Saez (1991) et Veltz (1996). Nous assistons à un renouvellement de cette problématique, qui renvoie aussi bien à l'observation des mutations extrêmement importantes du monde sur le plan 
technologique - vitesse, temps réel, flux tendu, connectivité et ubiquité -, que sur le plan idéologique avec la référence à la notion de réseau en tant que nouveau paradigme de la période postindustrielle. À la liaison entre ces deux acceptions, la réflexion sur les réseaux culturels relève autant des dernières technologies - transmissions de données, d'images, de sons, création empruntant les nouveaux supports médiatiques et informatiques -, que des possibilités matérielles de productions cinématographiques, musicales, théâtrales et artistiques de tous ordres. Celles-ci dépendent des potentialités de fécondation culturelle, mais bien évidemment des ressources financières que des partenaires privés et publics sont prêts à mettre dans les différentes opérations (Wolff, 1995).

\section{Les réseaux de villes dans le Grand Ouest}

3 Les réseaux de villes se définissent comme la conjonction "d'une évolution socioéconomique et de réactions politiques et institutionnelles des élus locaux» (Baudelle, Buléon, 1999) devant un monde en mutation profonde à travers l'internationalisation économique. Ces constructions institutionnelles plus ou moins solides fonctionnent dans des logiques qui peuvent varier entre une approche globale du développement des villes appartenant au même réseau à une action limitée portée par un projet de réalisation d'un équipement commun à plusieurs agglomérations comme par exemple une autoroute. Divers réseaux de villes, résultant d'une convergence entre la DATAR et les aspirations des milieux locaux, débouchent sur la réalisation d'expériences différentes, mais toutes mues à certaines occasions, par une volonté de s'allier pour défendre des intérêts communs face à des entreprises, à l'Europe ou à l'État et ses grandes administrations. Ces logiques, entre un engagement global et une participation axée sur une action, se rencontrent dans les réseaux de villes qui participent à la dynamique des espaces du Grand Ouest.

4 La Conférence des grandes villes de l'Ouest, née en 1990 et composée d'Angers, de Brest, de Nantes, du Mans et de Rennes appuie quatre axes: aménagement du territoire, développement économique, enseignement supérieur-recherche et actions culturelles. Les maires et les secrétaires de cabinet se rencontrent deux fois par an pour évoquer des questions communes avant qu'elles ne soient reprises par des instances nationales. En matière économique, les difficultés sont présentes et la concurrence des technopoles de ce territoire freine sans doute la volonté de développer une politique commerciale et de promotion collective. Concernant les infrastructures et en particulier la ligne à grande vitesse - LGV - Atlantique, elle a permis dans une première phase de faire une proposition collective de tracé à la SNCF et a fortiori à l'État. Il est vrai avant qu'intervienne la question du contournement du Mans par la LGV opposant les élus manceaux à ceux des autres villes du réseau. L'enseignement supérieur et la recherche permettent aux acteurs politiques locaux et aux représentants de l'État de définir une stratégie de complémentarité disciplinaire et scientifique entre les différentes universités, les grandes écoles et les centres de recherche de l'Ouest (Chevalier, Poussard, 1999).

5 Le réseau des villes moyennes bretonnes - Saint-Brieuc, Quimper, Saint-Malo et Vannes défend trois actions principales à caractère économique avec la mise en place d'un réseau audiovisuel de conférences, la réalisation d'un club d'entreprises et la politique de promotion touristique. La création d'une quatrième université en Bretagne, sise à Lorient 
et Vannes, répond à une volonté universitaire et culturelle locale de rapprochement de ces villes.

6 Le réseau normand ou plutôt l'association «Normandie Métropole » de coopération intégrée - Caen, Rouen et Le Havre - créée au début des années 1990, a érigé son action autour des questions des infrastructures, de l'enseignement supérieur, de la promotion des trois villes et de l'action culturelle.

7 À côté de ces réseaux de ville à large spectre d'intérêts, d'autres à vocation plus réduite existent comme l'axe Alençon-Le Mans-Tours qui vise surtout la réalisation d'une infrastructure autoroutière ayant des retombées économiques pour les villes concernées. Il s'agit plus d'un groupe de pression que d'un véritable réseau de villes.

8 L'Ouest de la France, comme d'autres régions - Poitou-Charentes, Midi-Pyrénées, Auvergne - connaît un développement de plusieurs réseaux de villes aux collaborations plus ou moins ponctuelles, qui tentent de répondre aux évolutions rapides et profondes des territoires. L'Europe, mais également Paris, dont l'accessibilité est améliorée avec la LGV Atlantique, ont provoqué pour les élus des villes et souvent des régions concernées, l'émergence d'un esprit d'ouverture, d'écoute et de complémentarité à côté de la sourde lutte ou concurrence que ces villes se sont souvent livrées. Dans plusieurs de ces réseaux, des considérations culturelles sont avancées, souvent comme priorité secondaire de leur programme de collaboration. Qu'en est-il exactement?

\section{Des réseaux culturels à géométrie variable}

9 La mise en réseau est une pratique encore assez limitée, surtout si l'on regarde leur efficacité dans cette phase de démarrage. Les entreprises à travers leur organisation mettent sur pied des réseaux maillant les territoires et en même temps elles sont de plus en plus déconnectées du milieu local dans lequel elles se sont développées. Les villes, les institutions ou les associations fonctionnent elles aussi en réseau à travers le partage de projets, d'expériences à moyen ou à long terme et d'opérations longues et pérennes ou uniques et éphémères. La culture participe à ces réseaux de villes, mais elle crée des réseaux qui échappent à la logique précédente. Pour cela nous nous interrogeons sur la mise en place de coopérations et de coproductions qui tissent des toiles entre différents partenaires culturels auxquels peuvent s'associer des institutions ou des partenaires privés.

10 Les réseaux culturels sont à la croisée des chemins entre les stratégies de différents acteurs appartenant aux cercles - économique, politique, administratif, idéologique, relationnel voire affectif - et qui interviennent à divers degrés dans la politique culturelle des collectivités. La réflexion porte sur la pertinence d'une coopération culturelle au sein des divers réseaux de ville. Mais il faut souligner que derrière ce terme de "culture " nous rencontrons des réalités multiples et bien différentes. Déjà la culture se décline entre des approches antagonistes, culture élitiste, culture populaire, culture officielle et culture officieuse, culture classique et culture innovante. Les formes culturelles s'appuient sur des pratiques très diverses comme le théâtre, l'opéra, la musique, le cinéma, les arts plastiques, les bibliothèques, les musées. Même si différentes expériences culturelles sont évoquées, nous nous cantonnons uniquement à l'analyse des réseaux culturels officiels autour de la création et de la diffusion du théâtre, de la musique classique et de l'opéra. Pour beaucoup d'élus, cette trilogie représente le socle d'une 
certaine conception de la culture, même s'ils favorisent aussi d'autres expressions culturelles.

11 La culture apparaît pour les élus comme un nouveau sésame qui permettrait de désamorcer des tensions sociales et économiques ou de relancer un développement local. Cependant les villes et les élus privilégient tel ou tel aspect culturel - création d'un festival, rayonnement d'un orchestre, réalisation d'équipements culturels - qui souvent servent de faire-valoir pro-domo. Les clivages se renforcent entre les grandes agglomérations et les rivalités historiques réapparaissent souvent. Ainsi l'émergence de Nantes comme métropole économique de l'Ouest irrite aussi bien Angers que Rennes, la capitale traditionnelle et culturelle de cet espace. Les villes et les différentes formes de culture tissent des liens, qui jouent un rôle non négligeable dans le développement des cités. Au sein des discours et des réalisations des gouvernements locaux, la production culturelle tend à remplacer des formes économiques obsolètes en investissant des lieux abandonnés comme les usines, les entrepôts, les casernes ou les gares. À Nantes la récupération d'une partie de l'ancienne usine LU crée ainsi un lieu culturel renommé - le Lieu Unique -, qui participe symboliquement à la dynamique globale de cette métropole. À Angers, les anciens abattoirs transformés en espace d'expérimentation culturelle contemporaine, jouent à une autre échelle un rôle similaire. Pour plusieurs élus la culture doit accompagner les changements positifs de leur ville en termes de croissance de l'emploi stratégique (Nantes et Rennes), de patrimonialisation (Angers, Brest, Caen, Le Mans), ou d'identité locale transcendant les disparités socio-économiques. L'observation $\mathrm{du}$ fonctionnement des infrastructures culturelles dépasse le cadre d'une approche purement géographique. Il s'avère pertinent de repérer l'organisation des manifestations en particulier au niveau des coopérations qui peuvent se tisser entre l'ensemble des acteurs appartenant à des territoires et à des organismes différents. L'analyse des rapports entre producteurs, responsables administratifs et politiques est à retenir (Le Gales, 1994).

12 Les réseaux culturels en fonction de leur objet et de leur réputation s'inscrivent dans des registres larges, du local à l'international. Ils appartiennent à deux logiques contradictoires et complémentaires à la fois. Un réseau plus ou moins informel basé sur des relations multiples lie les producteurs, les acteurs et les artistes au gré d'aléas imprévisibles. Face à cette construction à géométrie affective et territoriale indécise et mobile, les réseaux de villes mettent en place une coordination de leur potentiel culturel dans une logique fonctionnelle. Les rapprochements entre ces deux types de réseaux ne sont pas évidents, car ils opposent deux visions de la culture, l'une plus créatrice et iconoclaste, l'autre plus instrumentaliste et fonctionnaliste. Les grandes villes subventionnant largement certains équipements et manifestations, orientent de plus en plus leurs politiques culturelles qui $a$ priori s'opposent à toute mise en réseau susceptible d'écorner leur autonomie et leur image de marque. Pourtant la culture contrairement aux enjeux économiques, ne comporte pas les mêmes éléments d'inertie. Cependant, il n'est pas évident de repérer les opérations communes à l'ensemble des membres d'un même réseau de villes.

13 Les équipements culturels des trois régions ne sont pas en cause. Dans ce domaine, des rattrapages ont eu lieu, en particulier au profit des villes moyennes. Mais des malentendus fragilisent la volonté des acteurs politiques locaux. Les villes considèrent les réseaux culturels, comme des constructions boiteuses, qui doivent se plier à leur politique d'animation culturelle et/ou de marketing urbain. Mais, en amont de cette réflexion sur 
les réseaux culturels, se pose une question de fond sur les réseaux de villes. Chaque partenaire n'apporte pas la même chose - moyens économiques, humains et techniques et en attend des retombées globales mais spécifiques par rapport à son aspiration propre. Cette notion de réseau institutionnel, implicitement imposée par des technocrates et des instances économiques locales, plus que souhaitée au début par de nombreuses municipalités, soulève déjà des questions quant au fonctionnement réel de ces nouvelles constructions de gestion des territoires.

14 La loi du 2 mars 1982 et ses décrets d'application, relative aux droits et libertés des collectivités - communes, départements et régions -, dite loi de décentralisation a laissé de côté la sphère culturelle, à l'exception des bibliothèques centrales de prêts et des archives relevant des départements. Cette décentralisation s'est traduite par un renforcement de l'institutionnalisation des activités culturelles. La mise en place de commissions, de services et d'organismes culturels renforce les politiques publiques culturelles. Entre villes, départements et régions, la même logique induite par le processus de décentralisation est mise en œuvre. Les différentes collectivités locales, l'État et Bruxelles, conduisent leur propre politique culturelle. Cependant, ce sont surtout les cités importantes et les régions qui développent cette politique culturelle. Cette situation débouche sur des engagements culturels multiples entre les différentes collectivités locales qui parfois se concurrencent. Les politiques de décentralisation culturelle renforcent les capitales régionales par l'installation des Directions Régionales de l'Action Culturelle - DRAC - et par le soutien apporté à de gros équipements ou à des compagnies reconnues. Même si le désengagement de l'État se poursuit, les capitales régionales bénéficient d'interventions substancielles. C'est ainsi que le Théâtre National de Bretagne - TNB - est une structure régionale importante avec un budget dépassant les 50 millions de francs. L'État ne favorise pas la constitution de réseaux culturels entre les agglomérations. Il subventionne aux côtés des collectivités locales certains équipements et structures autonomes. Mais cela n'empêche pas l'affirmation d'identités culturelles fortes, comme en Bretagne où à travers différentes formes un réseau culturel existe et produit des spectacles à l'initiative non seulement de Rennes mais aussi des autres cités (fig. 1). 


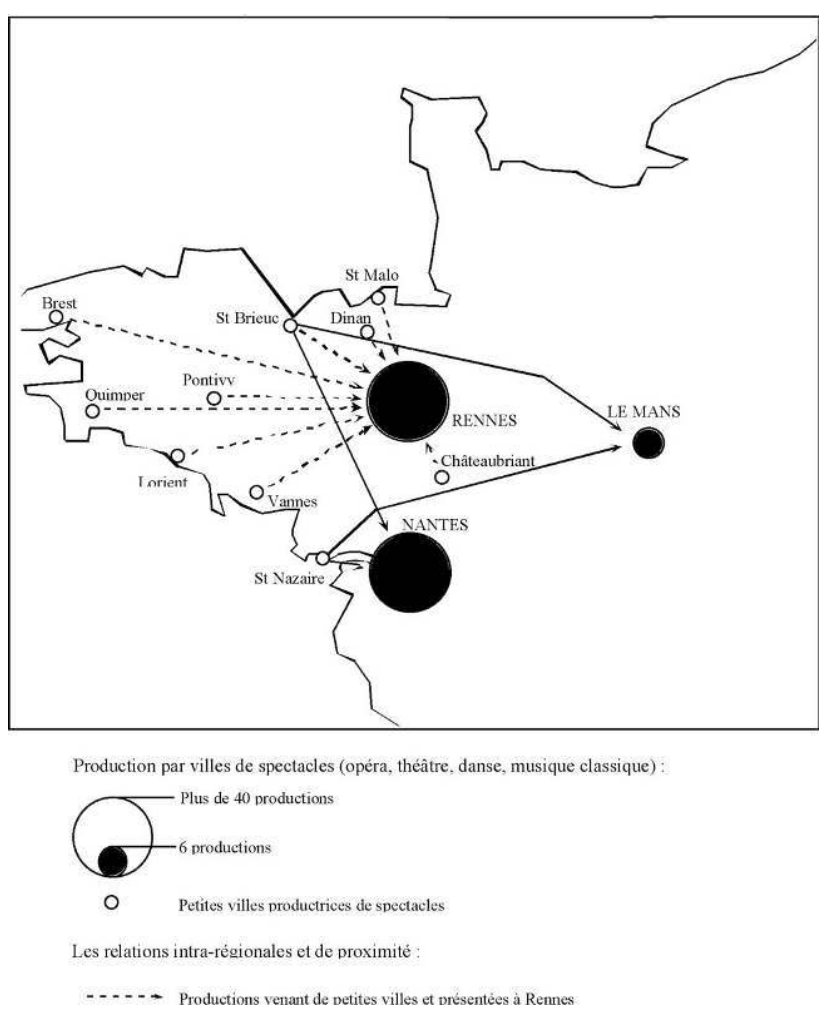

Si les villes interviennent pour étudier une mise en coopération d'équipements ou d'activités, c'est bien souvent par souci de maîtriser les dépenses publiques. Cette préoccupation est récente et elle n'empêche pas la poursuite de politique d'équipements identiques dans des agglomérations peu éloignées les unes des autres. Il s'agit là d'un enjeu de développement local et d'un argument d'efficacité du pouvoir local, intégré dans une politique de marketing territorial à effet interne et externe. Néanmoins les villes ne possèdent pas toutes la palette complète des équipements les plus prestigieux - opéra, grande pinacothèque, théâtre - impliquant un modus vivendi par défaut. Donc devant les coûts de plus en plus élevés, les agglomérations s'engagent vers des formules de partenariat entre différents intervenants publics et privés. C'est dans ce cadre-là que se développent des réseaux culturels intégrés aux réseaux de villes.

Cette mise en place d'un réseau culturel requiert une réelle volonté de collaboration entre différents acteurs. Les rivalités entre communes, départements, régions et services de l'État gênent l'émergence d'une politique propre pour bâtir en premier lieu les conditions de coopération entre cités d'un même réseau et ensuite articuler les réseaux culturels à géométrie variable aux réseaux de villes.

\section{La pertinence des réseaux institutionnels et culturels}

Les villes de l'Ouest, au même titre que la plupart des cités françaises depuis les lois de 1983, connaissent un développement important de leur vie culturelle. Il s'agit d'en repérer les principales manifestations pour voir comment elles s'inscrivent ou non dans les réseaux institutionnels de villes et dans les réseaux culturels aux mailles beaucoup plus larges et souples. 

un écho au plan national. Les festivals occupent une position marquante dans le paysage culturel d'une cité par le rituel des rencontres et les retombées médiatiques et économiques induites. Le nombre d'opérations éphémères caractérise une volonté locale de créer et de partager et il n'existe pas entre ces spectacles de qualité des coordinations entre les agglomérations de l'Ouest. Pourtant l'activité cinématographique bien représentée avec le festival Premiers plans et le festival du Scoop à Angers, le festival du Court métrage à Brest, le festival Travelling à Rennes, le festival des Trois continents à Nantes ou le festival de Deauville, pourrait déboucher sur des échanges et une diffusion entre les villes d'une partie des films présentés. Il en est de même avec le Festival Fin de Siècle et la Folle journée à Nantes, les Transmusicales et les Tombées de la nuit à Rennes ou le festival de Jazz du Mans.

Dans le cadre des festivals, les relations se situent entre le comité de pilotage et les producteurs, les metteurs en scènes, les troupes de théâtre ou les formations musicales. Ces contacts passent par des agents culturels, des conseillers culturels d'ambassade, mais surtout par des réseaux informels de connaissance. Pour ces manifestations, les réseaux de villes ne jouent aucun rôle officiel.

L'art lyrique est soutenu par une politique volontariste de partenariat. Les coproductions sont encouragées par «Alliance Opéra ", un groupement de trois partenaires - Crédit local de France, Air France et France 3 -, n'aidant que des spectacles montés au moins par quatre coproducteurs. Donc devant ce mécanisme de subventionnement des opéras, il est souvent hors de question de trouver l'ensemble des producteurs dans une même région. Ce type de réseaux culturels dépend d'un partenariat public-privé, permettant tant aux entreprises qu'aux collectivités de produire des spectacles et des festivals de qualité de plus en plus lourds financièrement. Ce processus est appelé à se développer.

21 La production théâtrale connaît une situation différente. Il n'existe rien de comparable à Alliance Opéra. Le coût de création d'une pièce est moins élevé en général que celui d'un opéra. Dans les Pays de la Loire, le Nouveau Théâtre d'Angers et la Scène Nationale de Saint-Nazaire ont coproduit en 1995 "Médéa » de Sénèque. Le directeur du Théâtre National de Bretagne quant à lui souhaite développer des coproductions bretonnes réunissant les différentes compagnies. Cependant ce discours est encore assez rare aussi bien dans la bouche des directeurs de compagnies que dans celle des responsables culturels des villes. Les coproductions interrégionales et internationales sont synonymes de qualité et de prestige. Il faut souligner qu'il n'est jamais question de travail ou d'œuvre en réseau mais systématiquement de coproduction sous la responsabilité d'un producteur délégué. En prenant l'exemple du Royal de Luxe, cette troupe de théâtre de rue, à la renommée internationale solidement établie, basée et soutenue depuis son arrivée dans les années 1980 par la municipalité et la ville de Nantes, entretient des relations multiples et diversifiées, qui vont de la Chine à l'Amérique centrale en passant par de nombreuses villes européennes mais échappent à toutes tentatives de mise en réseau institutionnel.

Les actions culturelles dépendent des outils, des équipes et des acteurs. Les situations divergent en fonction de la taille, des héritages de ces troupes ou de ces manifestations et des metteurs en scène choisis. Les coproductions sont souvent la règle, et celles-ci font fi de notre espace de référence. Quelques exemples pris dans l'actualité récente indiquent des relations extra régionales voire internationales. La création d' « un bal masqué » opéra de Verdi en 1995, est le fait d'une coproduction réunissant Avignon, Caen, Lausanne, 
Nantes, Rennes et Rouen. La saison 1997-1998 associe à des troupes locales des compagnies étrangères.

Trois types de réseaux se distinguent les uns des autres. Le réseau régional qui repose sur les villes de l'Ouest, le réseau national avec pour certaines villes des relations très fortes avec Paris et pour d'autres des liens beaucoup plus larges qui évitent la capitale et enfin le réseau international, avant tout européen. Ces réseaux culturels ne recoupent pas la politique menée par le réseau de villes de l'Ouest. La vitalité culturelle du réseau de villes s'appréhende à travers les manifestations organisées durant plusieurs saisons de suite. En reprenant les programmations (danse, musique classique, opéra et théâtre) pour la saison 1997-1998, les villes de Nantes, de Rennes et d'Angers devancent celles du Mans et de Brest, qui toutes deux ne possèdent pas d'opéras (fig. 2).

Figure 2 : Les relations culturelles entre les villes de l'Ouest (saison culturelle 1997-1998)

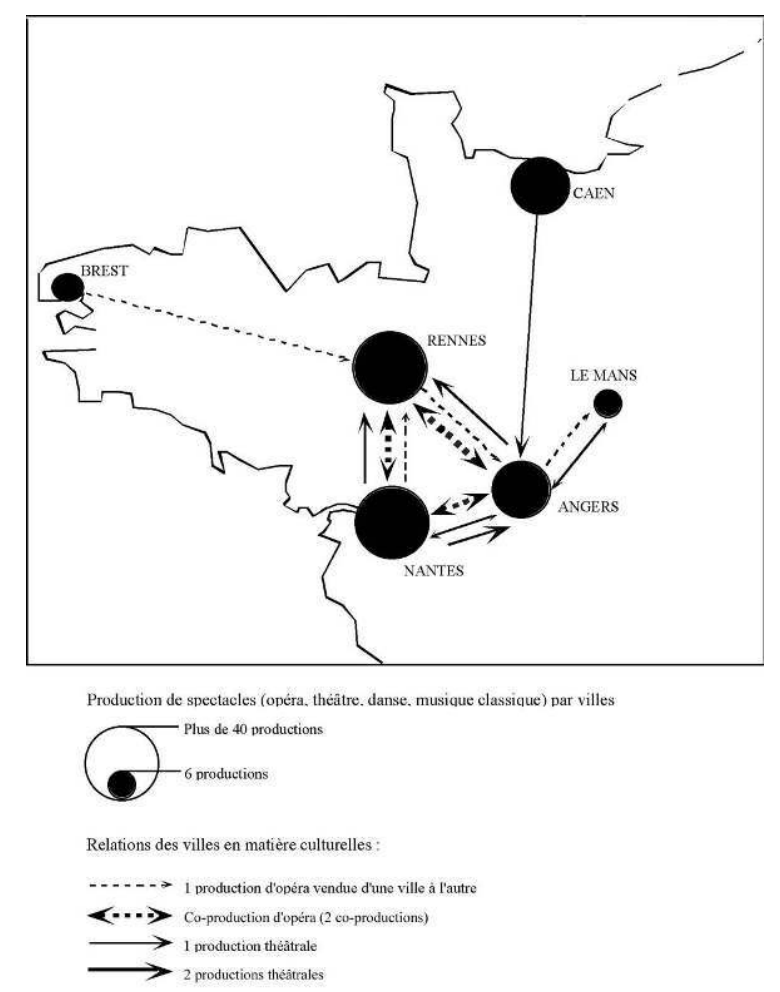

Rennes et Nantes présentent la plus grosse production avec une quarantaine de spectacles. Malgré la suprématie universitaire et la tradition culturelle de la capitale bretonne, Nantes devance Rennes. Ce rééquilibrage culturel en faveur de la cité ligérienne s'inscrit dans un processus volontariste et renforce son rôle de métropole du Grand Ouest. Angers se situe au même niveau que Caen, la capitale de la Basse-Normandie.

L'art lyrique, aux moyens toujours plus importants, requiert une politique de coproductions. La saison 1996-1997 a vu la création «Les Réprouvés » entre Nantes et Angers. En 1997-1998 Nantes produit «Ariane à Naxos", qui est repris à Rennes, «Idoménée » coproduit par Angers-Nantes-Rennes est accueilli à Nantes. En 1998-1999 trois coproductions associent pour «Aïda » Angers-Nantes-Rennes, pour «Ciboulette » Angers-Rennes et pour « Amélie va au bal » Angers-Nantes.

En dehors de ces coopérations à l'intérieur du réseau de villes, les relations avec d'autres cités prédominent et dépassent les frontières régionales et nationales (fig. 3). Nantes et 
Rennes présentent une palette de liens géographiques différents. Nantes monte peu de spectacles avec Paris.

Figure 3 : Villes de l'Ouest et relations nationales en terme de culture (saison culturelle 1997-1998)
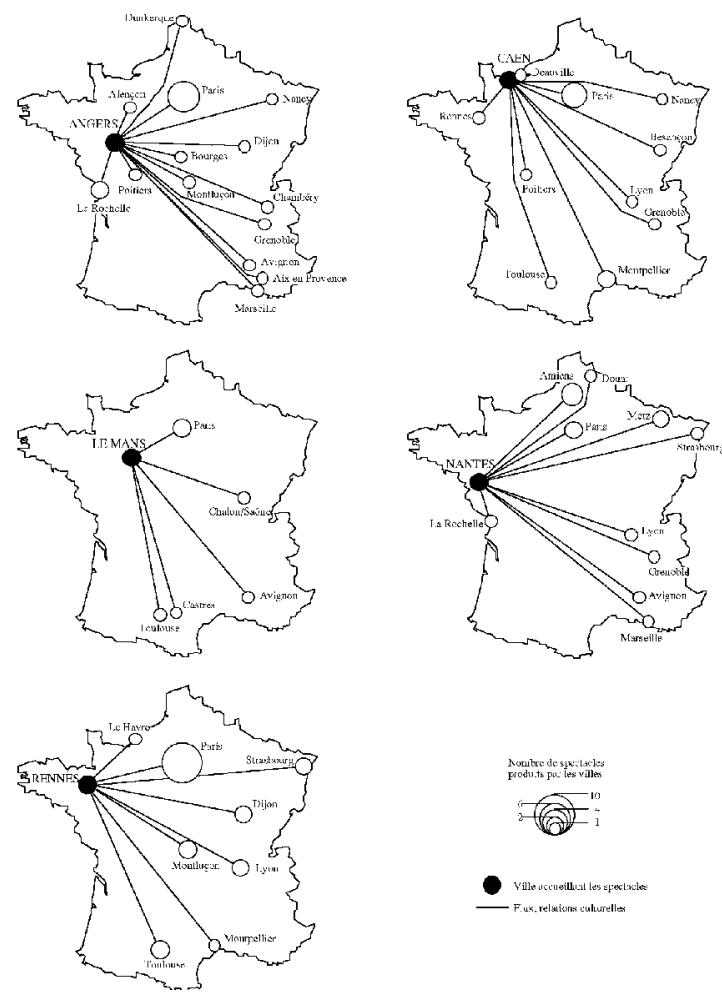

(source : programmations saison 1997-1998)

Ces coproductions concernent des villes du Nord et de l'Est, Amiens, Douai, Metz et Strasbourg et certaines agglomérations du Sud-Est, Avignon, Grenoble, Lyon et Marseille. L'agglomération rennaise tisse ses relations avant tout avec Paris, ignorant presque le réseau de villes de l'Ouest. Rennes et Paris créent plus de dix coproductions. Les autres villes entretenant des collaborations avec la capitale bretonne sont Lyon, Strasbourg, Dijon et Montluçon.

Angers et Caen regardent Paris. Caen tisse avec les autres villes françaises, beaucoup plus de liens qu'Angers. Est-ce son rôle de capitale régionale, ou la présence d'une université ancienne qui lui permet de s'ouvrir beaucoup plus ? Elle n'ignore pas Rennes. Angers a des relations avec Dijon et Nancy dans l'Est et dans le Sud-Est avec Avignon et Marseille. Quant au Mans, la proximité de la capitale lui fait de l'ombre culturellement. Mais cette ville a des liens avec Avignon et Toulouse.

En regardant l'ensemble des relations, Nantes se singularise par une politique d'évitement de la capitale. Une enquête sur une période plus longue pour évaluer effectivement cette situation serait sans doute intéressante. Les acteurs culturels des deux villes tissent peu de liens entre eux.

Les relations des villes de l'Ouest tournent le dos à la façade atlantique, qui devient une référence incantatoire en matière d'aménagement du territoire. En effet à part La Rochelle, les autres cités sont absentes. Par contre plusieurs agglomérations de l'Est et du Sud-Est établissent des échanges avec les villes de l'Ouest. C'est ainsi qu'Avignon est en 
relation avec Angers, Le Mans et Nantes; Grenoble avec Angers, Caen et Nantes ; Lyon avec Caen, Nantes et Rennes.

31 Si Nantes et Rennes occupent une place privilégiée sur le plan national, ce n'est pas le cas au niveau européen. Caen est largement plus ouverte sur l'Europe que les deux autres capitales régionales (fig. 4). Elle a reçu toujours pour la saison 1997-1998 des productions d'Allemagne, d'Espagne, du Royaume-Uni, d'Italie, de Russie, de Suisse et de Tchéquie. Les autres villes accueillent moins de spectacles étrangers.

Figure 4 : Productions européennes accueillies dans les villes de l'Ouest français (saison culturelle 1997-1998) - danse, théâtre et opéra

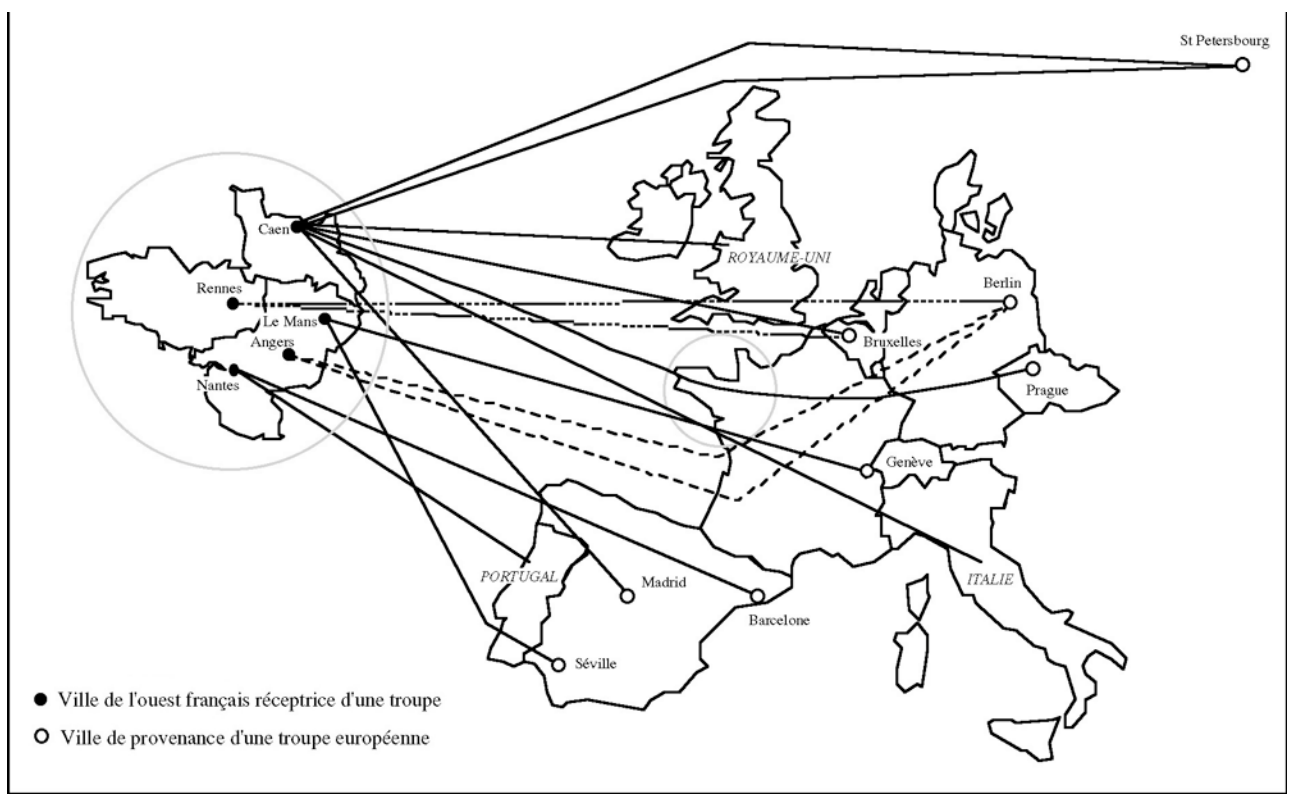

Les villes de l'Ouest proposent également des spectacles provenant des autres continents (fig. 5). Mais leur nombre est faible dans l'ensemble. Pourtant en tenant compte d'autres villes plus petites qui ont créé un festival de renom comme Lorient et le festival Interceltique, Saint-Florent-le-Vieil et son festival Occident-Orient de danse, les relations dépassent de loin les spectacles hébergés dans les grandes villes de l'Ouest. En prenant en compte les festivals de cinéma l'ouverture internationale de ces villes est confirmée. Les festivals de cinéma, sont exemplaires à cet égard. Il en est de même des orchestres et des chefs étrangers invités. Ces spectacles étrangers ne tournent pas entre les agglomérations du réseau institutionnel. Il serait souhaitable que quelques productions étrangères soient achetées par l'ensemble des villes. 
Figure 5 : Productions internationales (hors Europe) accueillies dans les villes de l'Ouest français (saison culturelle 1997-1998) - danse, théâtre et opéra

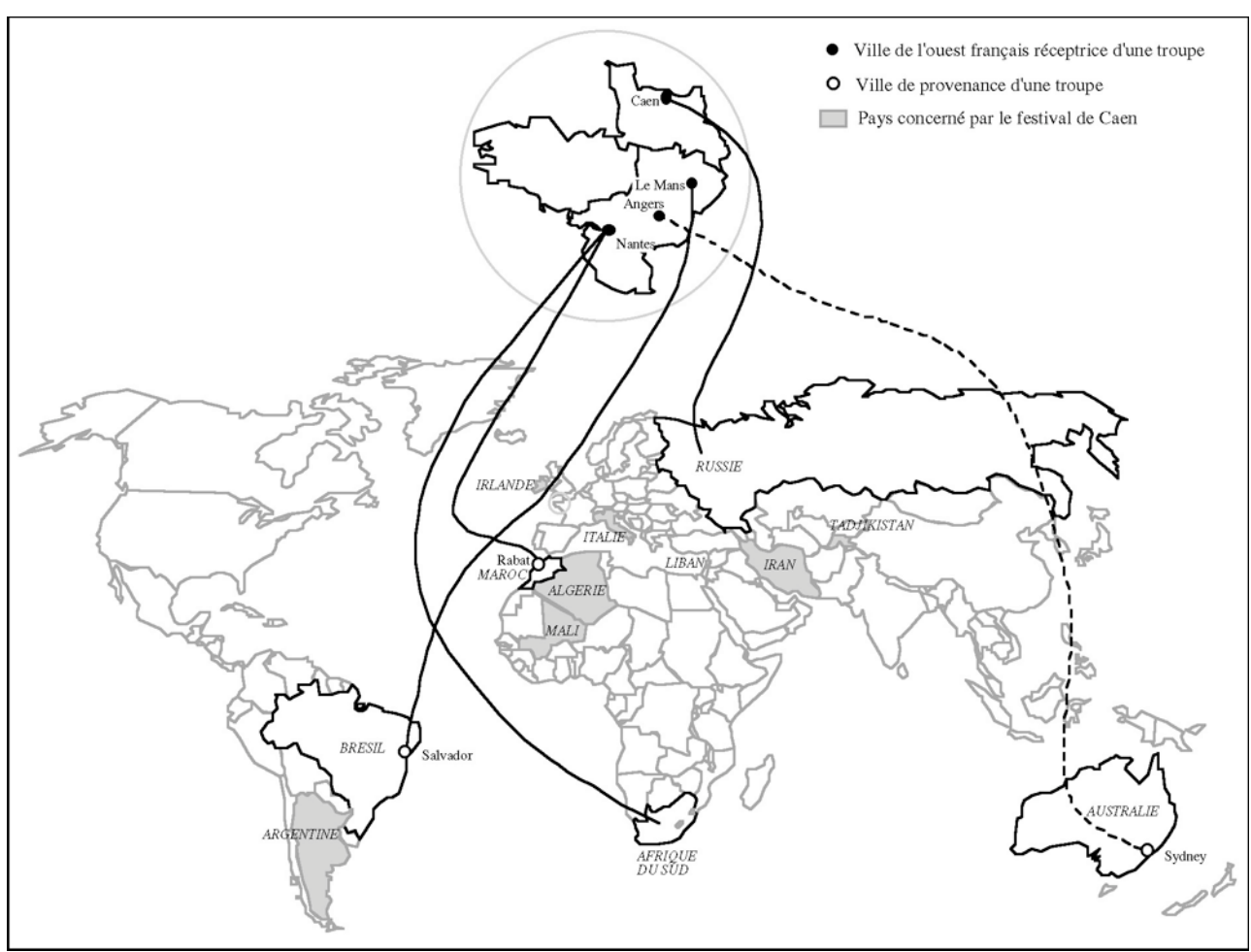

\section{Bilan de la politique culturelle du réseau des grandes villes de l'Ouest}

Lors de la mise en place du réseau des grandes villes de l'Ouest, la culture était absente des axes retenus - aménagement du territoire, développement économique et enseignement supérieur-recherche. La culture n'est prise en compte en tant que quatrième axe qu'en 1996, lors de la troisième conférence des maires. Pour combler cet oubli initial, la conférence des maires soutient la coopération entre les diverses institutions culturelles pour affirmer l'identité culturelle des quatre grandes villes de l'Ouest. Pour cela quatre pistes sont désignées : les écoles d'art, la coopération lyrique, les musiques nouvelles et les animations estivales. Ce rapprochement en termes de moyens est une initiative à souligner et à encourager dans d'autres domaines des activités culturelles.

Pourtant à côté de ces décisions, la volonté commune de mettre en place une politique culturelle est moins perceptible. Il est vrai que des questions d'aménagement régional priment sur la politique culturelle et en retardent l'application. Jusqu'à présent les grosses opérations culturelles ne reposent pas sur le réseau des grandes villes de l'Ouest, mais sur l'association des différentes collectivités territoriales à des partenaires économiques. Les bonnes intentions manquent de concrétisation et les raisons de cet échec sont doubles. D'une part, les élus considèrent la culture comme leur chasse gardée et ils l'intègrent à leur politique locale et à leur image de marque. D'autre part, les responsables des structures culturelles sont très jaloux de leurs prérogatives et ils se comportent souvent en petits ou grands « prêtres » de la Culture. Donc dans un domaine 
où, à première vue, il semble plus facile que dans les autres de concrétiser des actions en réseaux, il est très difficile de changer les mentalités tant des élus que des acteurs culturels.

Pour le réseau des grandes villes de l'Ouest, même si la politique culturelle n'est pas oubliée, peu de choses se font. L'appartenance à deux régions différentes, l'opposition entre les deux capitales régionales Nantes et Rennes et les rivalités entre les villes, même si politiquement elles sont toutes de sensibilité politique identique, se répercutent dans un domaine aussi sensible que la culture. D'ailleurs dans les Pays de la Loire la principale concrétisation d'une action culturelle commune à deux villes s'est faite en dehors de la mise en place de ces réseaux. Il s'agit de l'Orchestre National des Pays de la Loire - ONPL -, qui est né de la fusion des orchestres d'Angers et de Nantes - l'Orchestre Philharmonique des Pays de la Loire -, fortement encouragé par les deux villes ligériennes. Cette initiative s'est faite en dehors du réseau institutionnel, qui n'existait pas encore à cette époque, et elle illustre ce que pourrait être une politique culturelle bien comprise pour l'ensemble des agglomérations. Soulignons néanmoins qu'en 2001, un opéra régional à ambition nationale et européenne, est né de la volonté commune d'Angers et de Nantes de proposer des spectacles de qualité. Rennes souhaite se rapprocher de cette structure lyrique. Le coût très élevé d'équipements culturels de ce type implique une collaboration de villes proches qui s'inscrit dans une expérience positive depuis la création de l'ONPL. Il en est de même pour l'Orchestre de Bretagne, soutenu par la ville de Rennes, le Conseil régional, les quatre départements bretons, le ministère de la Culture, le quotidien régional Ouest France et la Banque Populaire de l'Ouest. Ces exemples illustrent le fonctionnement et les volontés effectives des villes de l'Ouest. Ils mettent l'accent sur la multiplicité des acteurs publics et privés et les limites de la politique culturelle des réseaux de villes.

La culture ne fut pas, au départ, une des priorités du réseau des grandes villes de l'Ouest. Pourtant la présence d'une armature urbaine « équilibrée » dans l'Ouest est un atout non négligeable. Mais cela ne suffit pas pour déboucher sur la mise en place de réseaux culturels impliquant l'ensemble géographique étudié. Ceci est renforcé par l'inadéquation entre réseaux de villes et réseaux culturels rencontrés. Au même titre que les réseaux de villes initiés par la DATAR et/ou des élus locaux, les réseaux culturels ont de la peine à s'affirmer par rapport aux directives territoriales d'aménagement. Même si les coûts de ces politiques culturelles n'ont aucune commune mesure avec la réalisation des réseaux de transports ou de télécommunication, les politiques locales sont encore peu impliquées dans ce domaine. Elles favorisent avant tout l'art lyrique et la musique au détriment des autres formes culturelles, tout en préservant l'autonomie de chaque ville. Dans ces réseaux culturels, les dimensions spatiales vont du local au supranational, elles nourrissent expériences locales et ouvertures internationales qui se mettent en place au coup par coup grâce au partenariat public-privé et aux liens interpersonnels. Les logiques d'acteurs divergent à travers leur appartenance institutionnelle ou non, leur rôle dans le monde politique et/ou culturel. Les élus locaux croisent les représentants de l'État, les protagonistes culturels s'appuient sur des partenaires privés et tous ces acteurs appartiennent à de multiples réseaux - politique, institutionnel, économique et artistique - qui se coupent et recoupent parfois mais dont la superposition est par définition impossible. 


\section{Conclusion}

La politique culturelle des réseaux de villes est une chose, les réalités sur le terrain en sont une autre et elles échappent en partie à ce catalogue de bonnes intentions. Pourtant la volonté politique de travailler en réseau, émerge lentement sous la pression des coûts croissants des équipements et des productions artistiques. Toutefois l'engagement des villes privilégie encore des actions prestigieuses initiées dans les grandes agglomérations et plus spécifiquement par les capitales régionales comme « La nuit des Allumés » relayée par « Fin de siècle » à Nantes à partir de 1996 ou « Les Transmusicales » à Rennes.

\section{BIBLIOGRAPHIE}

BAUdelle (G.), BulÉON (P.), 1999. - « Réseaux de villes entre logiques européennes et logiques locales ", dans J. Chevalier (coord.) Réseau urbain et réseaux de villes dans l'Ouest de la France, Collection Villes, Anthropos, Paris, p. 83-101.

BoNNEVILLE (M.), 1996. - « Villes en réseaux ou agglomérations en concurrence ? », dans P. Genestier (dir.) Vers un nouvel urbanisme, Paris, La documentation française, p. 71-77.

Cattan (N.), Pumain (D.), Rozenblat (C.), SAint-Julien (T.), 1994. - Le système des villes européennes, Paris, Anthropos, $201 \mathrm{p}$.

Chevalier (J.), Poussard (A.), 1999. - « Opportunités, politiques et réseaux : enseignement universitaire, recherche, production et diffusion culturelles », dans J. Chevalier (coord.), Réseau urbain et réseaux de villes dans l'Ouest de la France, Paris, Anthropos, coll. « Villes », p. 102-133.

DuPuY (G.), 1991. - L'urbanisme des réseaux : théories et méthodes, Paris, Armand Collin, 198 p.

-, 2000. - L'automobile et son monde, L'Aube, La Tour-d'Aigues, 217 p.

GUICHARD (O.), 1986. - Propositions pour l'aménagement du territoire, Paris, La Documentation française, $61 \mathrm{p}$.

LE GALÈs (P.), 1994. - « Villes en compétition », dans S. Biarez, J.-Y. Nevers (dir.), Gouvernement local et politiques urbaines, Grenoble, CERAT, p. 443-461.

LEVY (J.), 1996. - « Territoires et réseaux », dans T. Pacquot (dir.), Le monde des villes, Bruxelles, Éditions Complexe, p. 375-391.

MERLIN (P.), 1991. - L'urbanisme, Paris, PUF, coll. « Que sais-je ?», 128 p.

OfFNER (J.-M.), PumAin (D.), 1996. - Réseaux et territoires : significations croisées, La Tour-d'Aigues, L'aube, 281p.

PACQUOT (T.), Le monde des villes, Bruxelles, Éditions Complexe, p. 375-391.

PumAin (D.), 1992. - « Les systèmes de villes », dans A. Bailly, R. Ferras, D. Pumain (dir.), Encyclopédie de Géographie, Paris, Economica, p. 645-665. 
SAEZ (G.), 1991. - « Les niveaux de la politique culturelle métropolitaine, cohérence ou

fragmentation? », dans Y. Gasquy-Resch (dir.), Marseille-Montréal, Centres culturels cosmopolites, Paris, L'Harmattan, p. 266-280.

VeLTZ (P.), 1996. - Mondialisation, villes et territoires, PUF, Paris, 262 p.

WolfF (J.-P.), 1995. - « Réseaux et équipements culturels dans l'Ouest », dans J. Chevalier (dir.), Réseaux de villes dans l'Ouest, Le Mans, DATAR, $11 \mathrm{p}$.

\section{RÉSUMÉS}

Les réseaux culturels participent à la recomposition des territoires au même titre que les autres types de maillages - les infrastructures de communication, de télécommunication, les groupes économiques, les politiques de coopération institutionnelles... La culture est un enjeu économique et idéologique que les politiques essayent de contrôler. Dans cet article, il s'agit d'étudier la répartition de quelques équipements culturels et d'analyser les relations entre acteurs culturels et élus locaux dans l'Ouest de la France.

Cultural networks participate in the territorial restructuring in the same way as other types of networkings such as communications' infrastructures, telecoms, economic groups, institutional cooperation policies... Culture is an economic as well as ideological stake which political groups try to control. This article aims at analyzing both the distribution of certain types of cultural equipments and the relationship between the cultural actors and the political people in power in the West of France.

\section{INDEX}

Mots-clés : acteurs, géographie culturelle, pouvoir, réseau culturel, réseaux de villes, territoire Keywords : actors, cultural geography, cultural networks, power, territory, towns networks Index géographique : France, France de l'Ouest

\section{AUTEUR}

\section{JEAN-PIERRE WOLFF}

cirus CIEU - Toulouse, wolff@univ-tlse2.fr 